SUPPLEMENTARY INFORMATION SECTION

\title{
Grafting of nitrophenyl groups on carbon and metallic surfaces without electrochemical induction
}

Alain Adenier, Eva Cabet-Deliry, Annie Chaussé, Sophie Griveau, Florence Mercier, Jean Pinson, Christine Vautrin-U1*
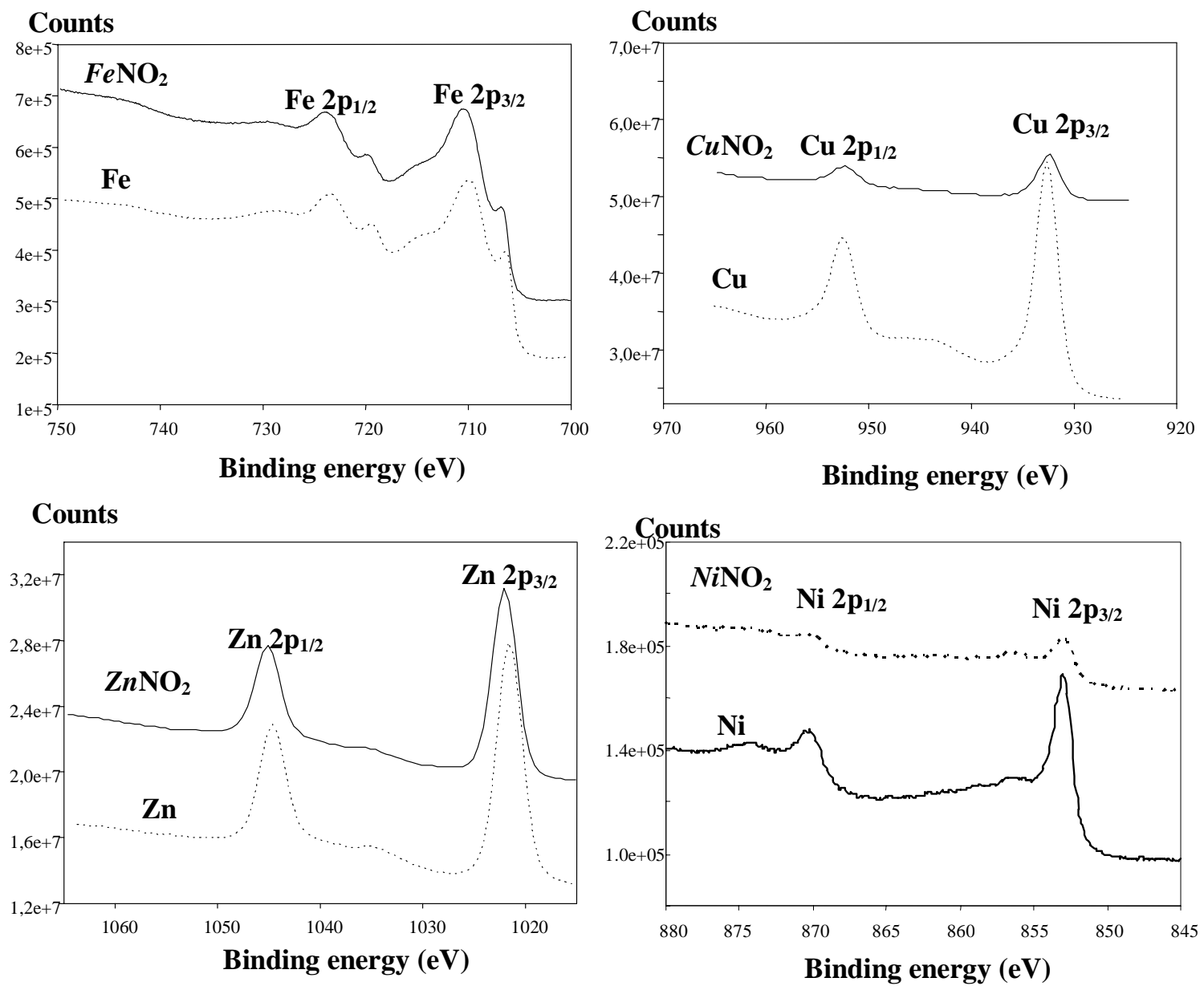

Figure S1. XPS spectra of bare and 10-modified surfaces: XPS spectra of substrate region. Modification of metallic surfaces was accomplished by dipping the material in a 10 mM PNBD solution in acetonitrile for $\mathbf{1}$ hour. 

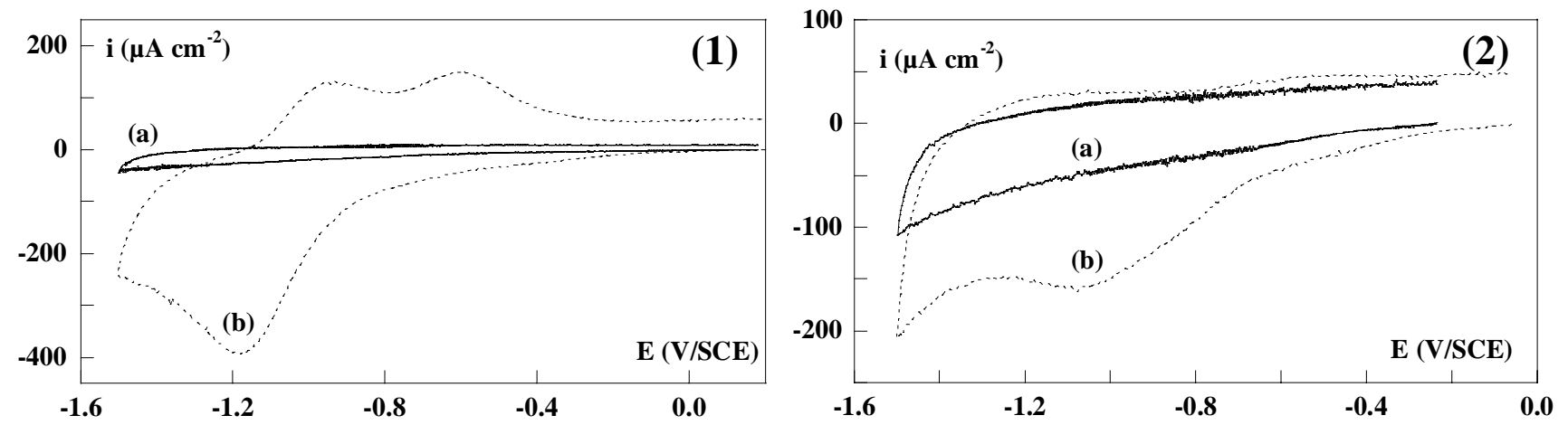

Figure S2. 1) Cyclic voltammograms in $\mathrm{ACN}+0.1 \mathrm{M} \mathrm{NBu}_{4} \mathrm{BF}_{4}$.obtained on (a) $\mathbf{G C}$ after immersion for 1 hour in 4-nitroaniline solution (10 $\mathrm{mM}$ in acetonitrile) and (b) GC after immersion for 1 hour in PNBD solution (10 $\mathrm{mM}$ in acetonitrile). 2) Cyclic voltammograms in $\mathrm{ACN}+0.1 \mathrm{M}$ $\mathrm{NBu}_{4} \mathrm{BF}_{4}$.obtained on (a) $\mathbf{F e}$ after immersion for 1 hour in 4-nitroaniline solution $(10 \mathrm{mM}$ in acetonitrile) and (b) Fe after immersion for 1 hour in PNBD solution (10 $\mathrm{mM}$ in acetonitrile). $\mathrm{v}=$ $0.2 \mathrm{~V} \mathrm{~s}^{-1}$.

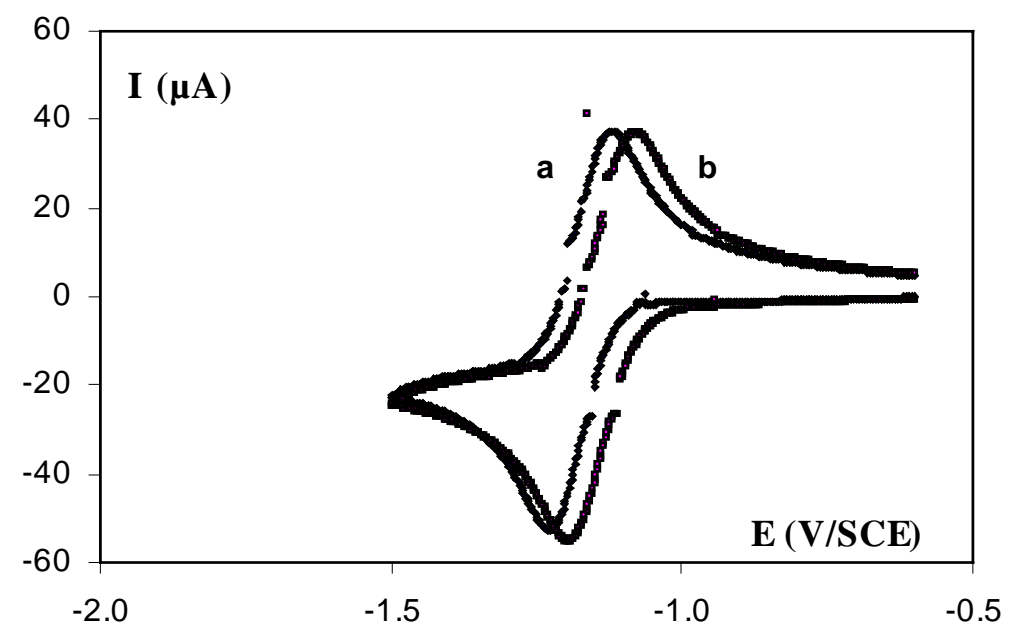

Figure S3. Cyclic voltammograms on a) bare GC and b) 10 -modified $\mathbf{G C N O}_{2}$ electrode in $1.21 \mathrm{mM}$ nitrotoluene in $\mathrm{ACN}+0.1 \mathrm{M} \mathrm{NBu}_{4} \mathrm{BF}_{4}$. Reference $\mathrm{SCE}, \mathrm{v}=0.2 \mathrm{Vs}^{-1}$. 


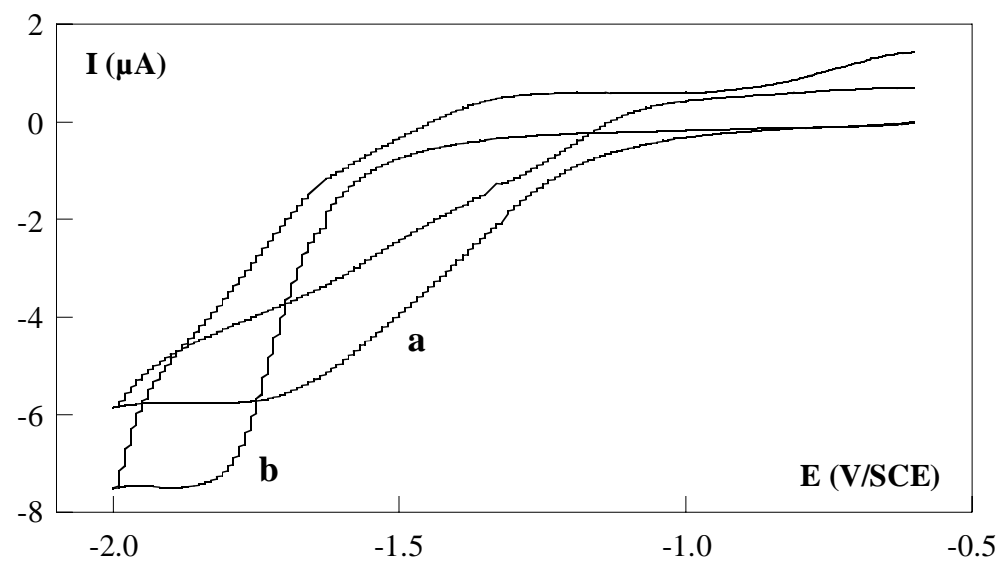

Figure S4. Cyclic voltammograms on a) bare Iron and b) 10-modified $\boldsymbol{F e N O}_{2}$ electrode in $1.21 \mathrm{mM}$ nitrotoluene in $\mathrm{ACN}+0.1 \mathrm{M} \mathrm{NBu}_{4} \mathrm{BF}_{4}$. Reference $\mathrm{SCE}, \mathrm{v}=0.2 \mathrm{Vs}^{-1}$. 
Investigation of the grafting solution, searching for cleaved substituents. We have searched the grafting solutions for the possible loss of substituents during the grafting reaction: nitrites from the reaction of PNBD. In order to obtain a sufficient concentration of nitrite, we used a high specific area carbon felt (Actitex 1500-1).

A sample of Actitex 1500-1 felt $(\mathrm{m}=0.455 \mathrm{~g})$ was immersed for one hour in a $10 \mathrm{mM}$ solution of PNBD $(10 \mathrm{~mL})$. Then a voltammogram of the solution was recorded between 0.5 and 1.1 V/SCE on a GC electrode (after dilution 50/50 with water and addition of $0.1 \mathrm{M}$ $\left.\mathrm{NEt}_{4} \mathrm{BF}_{4}\right)$, the voltammogram was identical to the background $(50 \mathrm{ACN} / 50$ water $+0.1 \mathrm{M}$ $\mathrm{NEt}_{4} \mathrm{BF}_{4}$ ) while a $2.86 \mathrm{mM}$ solution of sodium nitrite showed a drawn-out wave at about $0.8 \mathrm{~V} / \mathrm{SCE}$.

We also recorded the reading of a glass electrode in the final grafting solution. A 50/50 $\mathrm{ACN} /$ water solution without degassing gives a reading of 5.8 while the solution obtained after grafting of PNDB (and dilution as above) shows a value of 5.2.

These experiments indicate that no $-\mathrm{NO}_{2}$ groups are lost during the growth of the layer, but that protons are released in the process. 